\title{
Editorial: Special Issue on Photocatalytic Nanocomposite Materials (PNMs)
}

\author{
Detlef W. Bahnemann 1,2,*(D), Alexei V. Emeline ${ }^{1, *}$, Aida V. Rudakova ${ }^{1} \mathbb{D}$, Kirill M. Bulanin ${ }^{1}$ \\ and Ruslan V. Mikhaylov ${ }^{1}$ (D)
}

1 Laboratory "Photoactive Nanocomposite Materials", Saint-Petersburg State University, Ulyanovskaya str. 1, Peterhof, 198504 Saint-Petersburg, Russia; aida.rudakova@spbu.ru (A.V.R.); k.bulanin@spbu.ru (K.M.B.); ruslan.mikhaylov@spbu.ru (R.V.M.)

2 "Photocatalysis and Nanotechnology", Institut fuer Technische Chemie, Gottfried Wilhelm Leibniz Universitaet Hannover, Callinstrasse 3, D-30167 Hannover, Germany

* Correspondence: Detlef.bahnemann@spbu.ru (D.W.B.); alexei.emeline@spbu.ru (A.V.E.)

\section{check for}

updates

Citation: Bahnemann, D.W.; Emeline A.V.; Rudakova, A.V.; Bulanin, K.M.; Mikhaylov, R.V. Editorial: Special Issue on Photocatalytic

Nanocomposite Materials (PNMs). Catalysts 2021, 11, 587. https:// doi.org/10.3390/catal11050587

Received: 15 March 2021

Accepted: 28 March 2021

Published: 30 April 2021

Publisher's Note: MDPI stays neutral with regard to jurisdictional claims in published maps and institutional affiliations.

Copyright: (c) 2021 by the authors. Licensee MDPI, Basel, Switzerland. This article is an open access article distributed under the terms and conditions of the Creative Commons Attribution (CC BY) license (https:// creativecommons.org/licenses/by/ $4.0 /)$.
This Special Issue titled "Photocatalytic Nanocomposite Materials" (PNMs) is devoted to the research into new-generation PNMs, particularly for the processes of solar radiation energy conversion with its focus lying on the physicochemical principles of creating new materials with purposeful properties for their specific applications.

In their contribution titled "Rice Crust-Like $\mathrm{ZnO} / \mathrm{Ti}_{3} \mathrm{C}_{2} \mathrm{~T}_{x}$ MXene Hybrid Structures for Improved Photocatalytic Activity" Qui Thanh Hoai et al. report on their synthesis of novel two-dimensional $\mathrm{ZnO} / \mathrm{Ti}_{3} \mathrm{C}_{2} \mathrm{~T}_{\mathrm{x}}$ hybrid photocatalysts with modified surface areas using a simple calcination technique [1]. Under solar light illumination, the photocatalytic degradation efficiency of this hybrid photocatalyst appeared to be three-fold larger as compared to pristine $\mathrm{ZnO}$ which was attributed to several factors, such as ideal band alignment, Schottky barrier formation, and large surface area suggesting that the novel hybrid structure may be a potential candidate for removing organic pollutants in wastewater. Alexander I. Kokorin and coworkers studied the dynamics of charge carriers photogenerated in $\mathrm{TiO}_{2} / \mathrm{MoO}_{3}, \mathrm{TiO}_{2} / \mathrm{WO}_{3}$, and $\mathrm{TiO}_{2} / \mathrm{V}_{2} \mathrm{O}_{5}$ photocatalysts with mosaic structure that exhibited well-defined heterojunctions [2]. They observed that the accumulation of photoinduced charges occurs in two forms (i) filled electron traps corresponding to $\mathrm{Ti}^{4+} / \mathrm{Ti}^{3+}$ levels and (ii) $\mathrm{Mo}^{5+}$ centers thus demonstrating that light exposure of heterostructure photocatalysts with mosaic surfaces produces different types of charge-trapping centers. The latter appear to be capable of interacting with molecular oxygen yielding peroxo species thus providing an extended light-induced "self-cleaning" behavior. The combination of photocatalytic oxidation with biological treatment as studied by Liliana Bobirica and her colleagues was found to lead to high removal efficiencies of chlorophenols, while reducing the costs associated with the need to treat large volumes of aqueous solutions [3]. It could be shown that, regardless of the concentration of chlorophenol and its type, the working solutions become readily biodegradable following an initial irradiation by ultraviolet light with this irradiation period representing at most half of the total irradiation period necessary for the complete mineralization of the working solutions. These results could be correlated with the intermediates identified during the photocatalytic oxidation.

The "Noble Metal Modification of CdS-Covered $\mathrm{CuInS}_{2}$ Electrodes for Improved Photoelectrochemical Activity and Stability" was studied by Hiroshi Irie and coworkers who reported an efficient and stable photoelectrochemical (PEC) hydrogen $\left(\mathrm{H}_{2}\right)$ evolution using copper indium sulfide $\left(\mathrm{CuInS}_{2}\right)$ thin film electrodes [4]. Modification with a cadmium sulfide (CdS) layer led to improved charge separation at the interface between $\mathrm{CuInS}_{2}$ and $\mathrm{CdS}$ while, however, the photocorrosive nature of $\mathrm{CdS}$ induced poor stability of the photocathode. Further surface coating with an electrodeposited Pt layer over the CdS-covered $\mathrm{CuInS}_{2}$ photocathode prevented the CdS layer from making contact with the electrolyte solution, and enabled efficient $\mathrm{PEC} \mathrm{H}_{2}$ evolution without appreciable degradation thus 
indicating that the Pt layer functioned not only as a reaction site for $\mathrm{H}_{2}$ evolution, but also as a protection layer. Moreover, a surface protection using a noble metal layer made from $\mathrm{Au}$ or $\mathrm{Ag}$ was also effective for stable PEC carbon dioxide $\left(\mathrm{CO}_{2}\right)$ reduction yielding carbon monoxide as product. To further improve the photocatalytic performance of $\mathrm{SiO}_{2} / \mathrm{TiO}_{2}$ composites under visible light irradiation, curcumin-doped $\mathrm{SiO}_{2} / \mathrm{TiO}_{2}$ nanocomposites were synthesized by $\mathrm{Z}$. Yan et al. [5]. These authors found that doping of these $\mathrm{SiO}_{2} / \mathrm{TiO}_{2}$ composites with curcumin decreases the crystal size and improves the specific surface areas. Compared with bare $\mathrm{SiO}_{2} / \mathrm{TiO}_{2}$, the curcumin-doped $\mathrm{SiO}_{2} / \mathrm{TiO}_{2}$ resulted in enhanced photocatalytic reduction activity under visible light irradiation which was additionally also attributed to a synergetic effect between $\mathrm{SiO}_{2}$ and $\mathrm{TiO}_{2}$ in the $\mathrm{SiO}_{2} / \mathrm{TiO}_{2}$ nanocomposites. In their work titled "Tunable Composition Aqueous-Synthesized Mixed-Phase $\mathrm{TiO}_{2}$ Nanocrystals for Photo-Assisted Water Decontamination: Comparison of Anatase, Brookite and Rutile Photocatalysts" G. P. Demopoulos and coworkers present a sustainable solution process to synthesize tunable composition mixed-phase nanotitania photocatalysts in a continuously stirred tank reactor (CSTR) by modulating conditions such as $\mathrm{pH}, \mathrm{C}_{\mathrm{TiCl}}$ and time [6]. In particular, three mixed-phase $\mathrm{TiO}_{2}$ nanomaterials were produced, namely one predominantly anatase with brookite as minor component $\left(\mathrm{A}_{/ \mathrm{b}}\right)$, one predominantly brookite with minor component rutile $(\mathrm{B} / \mathrm{r})$, and one predominantly rutile with minor component brookite $\left(\mathrm{R}_{/ \mathrm{b}}\right)$ and evaluated as photocatalysts for the degradation of methyl orange. These new mixed-phase nanoTiO ${ }_{2}$ materials exhibit large specific surface areas, ranging from $90-125 \mathrm{~m}^{2} \mathrm{~g}^{-1}$, and first-order rate constants revealing essentially equivalent photocatalytic activity for anatase nanocrystals with either rutile (P25) or brookite (this work) domains.

K. P. Sapkota et al. studied the photocatalytic action of a series of copper(II)-oxidesingle-walled carbon nanotube composite photocatalysts and report that all of the asfabricated nanocomposites are effective photocatalysts with the photocatalytic action of the nanocomposites being remarkably higher than that of pristine $\mathrm{CuO}$ nanocrystals fabricated using the same route [7]. In their study titled "The Effect of Carbon Content on Methanol Oxidation and Photo-Oxidation at $\mathrm{Pt}_{-} \mathrm{TiO}_{2}-\mathrm{C}$ Electrodes" S. Sotiropoulos and coworkers analyzed the oxidation of methanol at $\mathrm{TiO}_{2}$-supported $\mathrm{Pt}$ electrodes with varied high surface area carbon content and $\mathrm{C} \div \mathrm{Ti}$ atomic ratio [8]. While the optimal conditions for the electro-oxidation of methanol were found at an atomic ratio of 1.5 , the intrinsic catalytic activity of the best $\mathrm{Pt}-\mathrm{TiO}_{2} / \mathrm{C}$ catalyst could be further improved upon UV illumination, the periodic application of which can also limit any eventual current deterioration. QuasiMIL-101(Cr) loaded Ceria catalysts for the Selective Catalytic Reduction (SCR) of $\mathrm{NO}_{\mathrm{x}}$ at low temperature have been prepared by $\mathrm{M}$. Lu et al. who report that an increase of the Ce content has a great influence on the catalytic properties of the catalyst [9]. While the presence of Ce promotes the conversion between $\mathrm{Cr}^{3+}$ and $\mathrm{Cr}^{5+}$ and increases the proportion of lattice oxygen, thus improving the activity of the catalyst, the catalyst will be peroxidized once the content of $\mathrm{Ce}$ is too high, resulting in a decline of the catalytic activity.

Christina Scheu and her research team show that by loading Ni(II) precursors, submonolayer $\mathrm{Ni}(\mathrm{OH})_{2}$ was uniformly distributed onto photocatalytic $\left[\mathrm{Ca}_{2} \mathrm{Nb}_{3} \mathrm{O}_{10}\right]^{-}$ nanosheets [10]. During heating in non-oxidative environments Ni nanoparticles form at $\geq 200{ }^{\circ} \mathrm{C}$ and undergo Ostwald ripening at $\geq 500{ }^{\circ} \mathrm{C}$. Ni loading of up to $3 \mathrm{wt} \%$ was demonstrated to enhance the rates of photocatalytic hydrogen evolution. Anna A. Murashkina et al. report the results of photoelectrochemical studies of binary $\mathrm{CdS} / \mathrm{TiO}_{2}$ and $\mathrm{WO}_{3} / \mathrm{TiO}_{2}$ as well as of ternary CdS $/ \mathrm{WO}_{3} / \mathrm{TiO}_{2}$ heterostructures based on titania nanotubes and planar structures demonstrating a significant difference in their behavior depending on the structure geometry and the character of the formed heterojunctions [11]. It is concluded that nanotube-based heterostructure electrodes can be characterized by a stochastic set of different heterojunctions while planar systems demonstrate well-ordered heterojunctions with a strictly defined electron transfer direction. Upon visible light irradiation a so-called Z-scheme best explains the photoexcitation and charge separation processes taking place in the ternary planar systems. Ricardo Gomez and coworkers have studied the "Hydrogen 
Production from Aqueous Methanol Solutions Using Ti-Zr Mixed Oxides as Photocatalysts under UV Irradiation" and observed that an increasing Zirconium content in the solid results in a higher generation rate of hydrogen when testing the Ti-Zr solids as photocatalysts [12].

The "Cooperative Catalytic Behavior of $\mathrm{SnO}_{2}$ and $\mathrm{NiWO}_{4}$ over $\mathrm{BiVO}_{4}$ Photoanodes for Enhanced Photoelectrochemical Water Splitting Performance" is reported by M. N. Shaddad et al. who present a very simple synthetic strategy to fabricate nanocomposite photoanodes [13]. In particular, the effect of a $\mathrm{SnO}_{2}$ buffer layer over $\mathrm{BiVO}_{4}$ films has been examined and the photoanode surface has been further modified with a crystalline nickel tungstate $\left(\mathrm{NiWO}_{4}\right)$ nanoparticle film to boost the PEC water oxidation. Furthermore, the incorporation of $\mathrm{NiWO}_{4}$ as co-catalyst over the $\mathrm{BiVO}_{4} / \mathrm{SnO}_{2}$ film is found to increase the interfacial electron transfer rate across the composite/solution interface. Jiri Rathousky and his team have studied "Immobilized $\mathrm{rGO} / \mathrm{TiO}_{2}$ Photocatalysts for the Decontamination of Water" optimizing an immobilized reduced graphene oxide $(\mathrm{rGO}) / \mathrm{TiO}_{2}$ composite by electrophoretic deposition (EPD) [14]. The presence of rGO had beneficial effects on the photocatalytic degradation of 4-chlorophenol in an aqueous solution with a marked increase in the photocatalytic degradation rate being observed, even at very low concentrations of rGO. This enhanced performance was explained by an increased formation of hydroxyl radicals that attack the 4-chlorophenol molecules while a direct charge transfer mechanism had only limited effect on the degradation. M. F. Atitar et al. presented a kinetic study of the "Photodegradation of the Herbicide Imazapyr and Phenol over Mesoporous Bicrystalline Phases $\mathrm{TiO}_{2}$ " and reported that mesoporous anatase-rutile $\mathrm{TiO}_{2}$ mixtures exhibit different structural properties depending upon the respective calcination process [15]. It is interesting to note that the material with the lowest anatase content (T-800) exhibits the highest photocatalytic activity in terms of initial reaction rate per unit surface area. Apparently, mixed-phase rutile-anatase photocatalysts exhibit enhanced photoactivity upon an increase of their rutile content.

The "Facile Synthesis of Heterojunctioned $\mathrm{ZnO} / \mathrm{Bi}_{2} \mathrm{~S}_{3}$ Nanocomposites for Enhanced Photocatalytic Reduction of Aqueous Cr(VI) under Visible-Light Irradiation" is reported by $\mathrm{X}$. Yuan et al. who showed that $\mathrm{ZnO} / \mathrm{Bi}_{2} \mathrm{~S}_{3}$ composites exhibit a sandwich-like structure with the $\mathrm{ZnO}$ nanoparticles randomly embedded between $\mathrm{Bi}_{2} \mathrm{~S}_{3}$ nanoflakes [16]. The observed enhanced performance of the $\mathrm{ZnO} / \mathrm{Bi}_{2} \mathrm{~S}_{3}$ photocatalysts is ascribed to an increased light harvesting performance and an effective separation and transfer of the photogenerated charge carriers across the heterojunction interface of the $\mathrm{ZnO} / \mathrm{Bi}_{2} \mathrm{~S}_{3}$ composites. $\mathrm{X}$. Wang et al. prepared and tested " $\mathrm{AgBr} /\left(\mathrm{Sr}_{0 \cdot 6} \mathrm{Bi}_{0 \cdot 305}\right)_{2} \mathrm{Bi}_{2} \mathrm{O}_{7}$ Heterostructured Composites: Fabrication, Characterization, and Significantly Enhanced Photocatalytic Activity" with the photocatalytic activity of their samples being evaluated by degrading methylene blue under visible light illumination [17]. AgBr/SBO composites were found to possess high stability and significantly enhanced photocatalytic performance with the latter being explained by enhanced light absorption and the separation of photoinduced electrons and holes at the interface of the $\mathrm{AgBr} / \mathrm{SBO}$ heterostructured composites. He, Zhang and $\mathrm{He}$ prepared " $\mathrm{MoS}_{2} / \mathrm{CdS}$ Heterostructures for Enhanced Photoelectrochemical Performance under Visible Light" and report that CdS nanoparticles immobilized on $\mathrm{MoS}_{2}$ sheets retain their original crystal structure and morphology [18]. These composites exhibit higher photoelectrochemical efficiencies compared with pure $\mathrm{MoS}_{2}$ nanosheets or CdS powder which is ascribed to increased light harvesting properties, as well as to the heterostructure decreasing the recombination rate of the photogenerated electron/hole pairs.

The "Characterization and Effect of $\mathrm{Ag}(0)$ vs. $\mathrm{Ag}(\mathrm{I})$ Species and Their Localized Plasmon Resonance on Photochemically Inactive $\mathrm{TiO}_{2}$ " has been studied by Jennifer Strunk and her research team who modified commercial $\mathrm{TiO}_{2}$ (anatase) with $\mathrm{Ag}$ nanoparticles at different nominal loadings (1-4\%) using a liquid impregnation method [19]. The prepared materials retained the anatase structure and contained a mixture of $\mathrm{Ag}^{0}$ and $\mathrm{Ag}^{\mathrm{I}}$ species. The effect of Ag loading on $\mathrm{TiO}_{2}$ has been studied for the photocatalytic reduction of $\mathrm{CO}_{2}$ to $\mathrm{CH}_{4}$ in a gas-solid process under high-purity conditions evincing that only in the case 
of $2 \% \mathrm{Ag} / \mathrm{TiO}_{2}$ the formation of $\mathrm{CH}_{4}$ from $\mathrm{CO}_{2}$ was observed. While an influence of the localized surface plasmon resonance (LSPR) effect of Ag has been verified, the results also indicated that a mixed oxidation state is beneficial for the photocatalytic performance. Peng Zhao and coworkers studied the "Enhanced Visible Light Photocatalytic Reduction of $\mathrm{Cr}(\mathrm{VI})$ over a Novel Square Nanotube Poly(Triazine Imide) $/ \mathrm{TiO}_{2}$ Heterojunction" and prepared $\mathrm{TiO}_{2}$-modified poly(triazine imide) (PTI) square nanotubes by a one-step molten salts method [20]. During the formation of the PTI square tube, $\mathrm{TiO}_{2}$ nanoparticles adhere to the surface of the square tube wall by strong adsorption, and eventually form a $\mathrm{PTI} / \mathrm{TiO}_{2}$ heterojunction. Its enhanced photocatalytic activity was mainly attributed to the efficient separation and transport of photo-induced electron-hole pairs and the high specific surface area within the heterojunction structure. The properties of "Network Structured $\mathrm{CuWO}_{4} / \mathrm{BiVO}_{4} / \mathrm{Co}-\mathrm{Pi}$ Nanocomposites for Solar Water Splitting" have been studied by B. Peng et al. [21]. The obtained $\mathrm{CuWO}_{4} / \mathrm{BiVO}_{4}$ exhibit high catalytic activity toward photoelectrochemical (PEC) water oxidation which are further improved for a $\mathrm{CuWO}_{4} / \mathrm{BiVO}_{4} / \mathrm{Co}-\mathrm{Pi}$ composite, in particular, for the oxygen evolution reaction (OER). This high activity for the PEC OER is attributed to the high specific surface area of the composite, the formation of a $\mathrm{CuWO}_{4} / \mathrm{BiVO}_{4}$ heterojunction accelerating the electron-hole separation, and the coupling of the Co-Pi co-catalyst with $\mathrm{CuWO}_{4} / \mathrm{BiVO}_{4}$, thus improving the charge transfer rate across composite/solution interface.

Following these original research articles 4 review papers are also included in this special issue. In their feature paper titled "Photoactive Heterostructures: How They Are Made and Explored" A. V. Emeline et al. present results of studies concerned with the development and exploration of heterostructured photoactive materials with their major attention focused on what are the better ways to form this type of materials and how to explore them correctly [22]. Regardless of what type of heterostructure, metal-semiconductor or semiconductor-semiconductor, is formed, its functionality strongly depends on the quality of heterojunction. In turn, it depends on the selection of the heterostructure components (their chemical and physical properties) and on the proper choice of the synthesis method. Several examples of the different approaches such as in situ and ex situ, bottom-up and topdown, are reviewed. At the same time, even if the synthesis of heterostructured photoactive materials seems to be successful, strong experimental physical evidence demonstrating true heterojunction formation are required. A possibility for obtaining such evidence using different physical techniques is discussed. Particularly, it is demonstrated that the ability of optical spectroscopy to study heterostructured materials is in fact very limited. At the same time, such experimental techniques as high-resolution transmission electron microscopy (HRTEM) and electrophysical methods (work function measurements and impedance spectroscopy) present a true signature of heterojunction formation. Therefore, whatever the purpose of heterostructure formation and studies is, the application of HRTEM and electrophysical methods is necessary to confirm that formation of the heterojunction was successful. M. Falah and K. J. D. MacKenzie focus on "Photocatalytic Nanocomposite Materials Based on Inorganic Polymers (Geopolymers): A Review" and state that although to date the principal applications of geopolymers have been seen as alternatives to Portland cement building materials, their properties make them suitable for a number of more advanced applications, including as photocatalytic nanocomposites for removal of hazardous pollutants from waste water or the atmosphere [23]. For this purpose, they can be combined with photocatalytic moieties such as metal oxides with suitable bandgaps to couple with UV or visible radiation, or with carbon nanotubes or graphene. In these composites the geopolymers act as supports for the photoactive components, but geopolymers formed from wastes containing oxides such as $\mathrm{Fe}_{2} \mathrm{O}_{3}$ show intrinsic photoactive behavior. This review discusses the structure and formation chemistry of geopolymers and the principles required for their utilization as photocatalysts. The literature on existing photocatalytic geopolymers is reviewed, suggesting that these materials have a promising potential as inexpensive, efficient and ecologically-friendly candidates for the remediation of toxic environmental pollutants and would repay further development. "Recent Advances in 
Niobium-Based Materials for Photocatalytic Solar Fuel Production" are summarized in a review and feature paper by B. N. Nunes et al. who conclude that semiconductors based on the Niobium pentacation are still shallowly explored, although the number of publications and patents on $\mathrm{Nb}(\mathrm{V})$-based photocatalysts has increased in the last years [24]. A large variety of $\mathrm{Nb}(\mathrm{V})$-based materials exhibit suitable electronic/morphological properties for light-driving reactions. Not only the extensive group of $\mathrm{Nb}_{2} \mathrm{O}_{5}$ polymorphs is explored, but also many types of layered niobates, mixed oxides, and $\mathrm{Nb}(\mathrm{V})$-doped semiconductors. Therefore, these authors provide a review of the latest developments of Niobium based photocatalysts for energy conversion into fuels, more specifically, $\mathrm{CO}_{2}$ reduction to hydrocarbons or $\mathrm{H}_{2}$ evolution from water. Additionally, the main strategies for improving the photocatalytic performance of Niobium-based materials are discussed. The topic of the final review of this special issue contributed by A. L. Chibac-Scutaru is: "Polymer Nanocomposites for Photocatalytic Applications" specifically focusing on polymer nanocomposites used as photocatalytic materials in fine organic reactions or in organic pollutants degradation [25]. The selection of the polymer substrates for the immobilization of the active catalyst particles is motivated by several advantages of these systems: environmental stability, chemical inertness and resistance to ultraviolet radiations, mechanical stability, low prices and ease availability. Additionally, the use of polymer nanocomposites as photocatalysts offers the possibility of a facile separation and reuse of the materials, eliminating thus the post-treatment separation processes and implicitly reducing the costs of the procedure. This review covers the polymer-based photocatalytic materials containing the most popular inorganic nanoparticles with good catalytic performance under UV or visible light illumination, namely $\mathrm{TiO}_{2}, \mathrm{ZnO}, \mathrm{CeO}_{2}$, or plasmonic $(\mathrm{Ag}, \mathrm{Au}, \mathrm{Pt}, \mathrm{Pd}) \mathrm{NPs}$. The study is mainly targeted on the preparation, photocatalytic activity, strategies directed toward the increase of photocatalytic efficiency under visible light and reuse of the hybrid polymer catalysts.

In summary, nanocomposite materials present an interesting class of photocatalysts offering, on the one hand, an improved separation of the photogenerated charge carriers at the interfaces between nanoparticles of different chemical composition. On the other hand, semiconductor particles with lower bandgap energies can be selected in a smart way to ensure the formation of electrons and holes exhibiting suitable one-electron reduction and oxidation potentials, respectively, following simultaneous photon absorption in two different materials and recombination of the "unneeded" charge carriers, e.g., in a ZScheme mechanism. This special issue provides an excellent and timely overview of this field. I wish to thank the authors of the publications for their valuable contributions, my colleagues and co-editors of this special issue Prof. Dr. Alexei Emeline, Dr. Aida Rudakova, Dr. Kirill M. Bulanin, and Dr. Ruslan Mikhaylov, and the editorial team of Catalysts for their kind support and fast response.

Acknowledgments: All authors gratefully acknowledge support from Saint Petersburg State University (SPBU) within the Project ID: 73032813.

Conflicts of Interest: The author declares no conflict of interest.

\section{References}

1. Ta, Q.T.H.; Tran, N.M.; Noh, J.-S. Rice Crust-Like ZnO/Tii $\mathrm{C}_{2} \mathrm{~T}_{\mathrm{x}}$ MXene Hybrid Structures for Improved Photocatalytic Activity. Catalysts 2020, 10, 1140. [CrossRef]

2. Kokorin, A.I.; Sviridova, T.V.; Konstantinova, E.A.; Sviridov, D.V.; Bahnemann, D.W. Dynamics of Photogenerated Charge Carriers in $\mathrm{TiO}_{2} / \mathrm{MoO}_{3}, \mathrm{TiO}_{2} / \mathrm{WO}_{3}$ and $\mathrm{TiO}_{2} / \mathrm{V}_{2} \mathrm{O}_{5}$ Photocatalysts with Mosaic Structure. Catalysts 2020, 10, 1022. [CrossRef]

3. Bobirica, L.; Bobirica, C.; Orbeci, C. Examination of Photocatalyzed Chlorophenols for Sequential Photocatalytic-Biological Treatment Optimization. Catalysts 2020, 10, 985. [CrossRef]

4. Takashima, T.; Fujishiro, Y.; Irie, H. Noble Metal Modification of CdS-Covered CuInS 2 Electrodes for Improved Photoelectrochemical Activity and Stability. Catalysts 2020, 10, 949. [CrossRef]

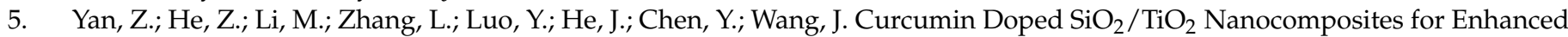
Photocatalytic Reduction of Cr (VI) under Visible Light. Catalysts 2020, 10, 942. [CrossRef] 
6. Chalastara, K.; Guo, F.; Elouatik, S.; Demopoulos, G.P. Tunable Composition Aqueous-Synthesized Mixed-Phase TiO 2 Nanocrystals for Photo-Assisted Water Decontamination: Comparison of Anatase, Brookite and Rutile Photocatalysts. Catalysts 2020, 10, 407. [CrossRef]

7. Sapkota, K.P.; Lee, I.; Hanif, M.A.; Islam, M.A.; Akter, J.; Hahn, J.R. Enhanced Visible-Light Photocatalysis of Nanocomposites of Copper Oxide and Single-Walled Carbon Nanotubes for the Degradation of Methylene Blue. Catalysts 2020, 10, 297. [CrossRef]

8. Papaderakis, A.; Spyridou, O.; Karanasios, N.; Touni, A.; Banti, A.; Dimitrova, N.; Armyanov, S.; Valova, E.; Georgieva, J.; Sotiropoulos, S. The Effect of Carbon Content on Methanol Oxidation and Photo-Oxidation at Pt-TiO ${ }_{2}-C_{\text {Electrodes. Catalysts }}$ 2020, 10, 248. [CrossRef]

9. Lu, M.; Hou, H.; Wei, C.; Wei, W.; Wang, G.-S. Preparation of Quasi-MIL-101(Cr) Loaded Ceria Catalysts for the Selective Catalytic Reduction of NOx at Low Temperature. Catalysts 2020, 10, 140. [CrossRef]

10. Zhang, S.; Diehl, L.; Wrede, S.; Lotsch, B.V.; Scheu, C. Structural Evolution of Ni-Based Co-Catalysts on $\left[\mathrm{Ca}_{2} \mathrm{Nb}_{3} \mathrm{O}_{10}\right]-\mathrm{Nanosheets}$ during Heating and Their Photocatalytic Properties. Catalysts 2020, 10, 13. [CrossRef]

11. Murashkina, A.A.; Baklev, T.V.; Artemev, Y.M.; Rudakova, A.V.; Emeline, A.V.; Bahnemann, D.W. Photoelectrochemical Behavior of the Ternary Heterostructured Systems CdS $/ \mathrm{WO}_{3} / \mathrm{TiO}_{2}$. Catalysts 2019, 9, 999. [CrossRef]

12. Pérez-Larios, A.; Rico, J.L.; Anaya-Esparza, L.M.; González-Vargas, O.A.; González-Silva, N.; Gómez, R. Hydrogen Production from Aqueous Methanol Solutions Using Ti-Zr Mixed Oxides as Photocatalysts under UV Irradiation. Catalysts $2019,9,938$. [CrossRef]

13. Shaddad, M.N.; Arunachalam, P.; Hezam, M.; Al-Mayouf, A.M. Cooperative Catalytic Behavior of $\mathrm{SnO}_{2}$ and $\mathrm{NiWO}_{4}$ over BiVO4 Photoanodes for Enhanced Photoelectrochemical Water Splitting Performance. Catalysts 2019, 9, 879. [CrossRef]

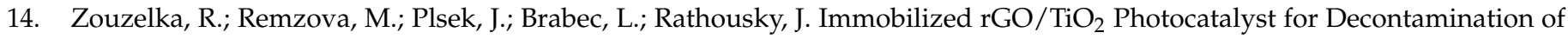
Water. Catalysts 2019, 9, 708. [CrossRef]

15. Atitar, M.F.; Ismail, A.A.; Dillert, R.; Bahnemann, D.W. Photodegradation of Herbicide Imazapyr and Phenol over Mesoporous Bicrystalline Phases $\mathrm{TiO}_{2}$ : A Kinetic Study. Catalysts 2019, 9, 640. [CrossRef]

16. Yuan, X.; Wu, X.; Feng, Z.; Jia, W.; Zheng, X.; Li, C. Facile Synthesis of Heterojunctioned ZnO/Bi2S3 Nanocomposites for Enhanced Photocatalytic Reduction of Aqueous Cr(VI) under Visible-Light Irradiation. Catalysts 2019, 9, 624. [CrossRef]

17. Wang, X.; Zhu, D.; Zhong, Y.; Wang, D.; Hu, C. AgBr $/\left(\mathrm{Sr}_{0.6} \mathrm{Bi}_{0.305}\right)_{2} \mathrm{Bi}_{2} \mathrm{O}_{7}$ Heterostructured Composites: Fabrication, Characterization, and Significantly Enhanced Photocatalytic Activity. Catalysts 2019, 9, 394. [CrossRef]

18. He, G.; Zhang, Y.; He, Q. $\mathrm{MoS}_{2} / \mathrm{CdS}$ Heterostructure for Enhanced Photoelectrochemical Performance under Visible Light. Catalysts 2019, 9, 379. [CrossRef]

19. Handoko, C.T.; Moustakas, N.G.; Peppel, T.; Springer, A.; Oropeza, F.E.; Huda, A.; Bustan, M.D.; Yudono, B.; Gulo, F.; Strunk, J. Characterization and Effect of $\mathrm{Ag}(0)$ vs. $\mathrm{Ag}(\mathrm{I})$ Species and Their Localized Plasmon Resonance on Photochemically Inactive TiO ${ }_{2}$. Catalysts 2019, 9, 323. [CrossRef]

20. Yan, X.; Ning, G.; Zhao, P. Enhanced Visible Light Photocatalytic Reduction of Cr(VI) over a Novel Square Nanotube Poly(Triazine Imide) $/ \mathrm{TiO}_{2}$ Heterojunction. Catalysts 2019, 9, 55. [CrossRef]

21. Peng, B.; Xia, M.; Li, C.; Yue, C.; Diao, P. Network Structured CuWO $4 / \mathrm{BiVO}_{4} / \mathrm{Co}-\mathrm{Pi}$ Nanocomposite for Solar Water Splitting. Catalysts 2018, 8, 663. [CrossRef]

22. Emeline, A.V.; Rudakova, A.V.; Mikhaylov, R.V.; Bulanin, K.M.; Bahnemann, D.W. Photoactive Heterostructures: How They Are Made and Explored. Catalysts 2021, 11, 294. [CrossRef]

23. Falah, M.; MacKenzie, K.J.D. Photocatalytic Nanocomposite Materials Based on Inorganic Polymers (Geopolymers): A Review. Catalysts 2020, 10, 1158. [CrossRef]

24. Nunes, B.N.; Lopes, O.F.; Patrocinio, A.O.T.; Bahnemann, D.W. Recent Advances in Niobium-Based Materials for Photocatalytic Solar Fuel Production. Catalysts 2020, 10, 126. [CrossRef]

25. Melinte, V.; Stroea, L.; Chibac-Scutaru, A.L. Polymer Nanocomposites for Photocatalytic Applications. Catalysts 2019, 9, 986. [CrossRef] 